\title{
Monoclonal antibody that recognizes an epitope of the sperm equatorial region and specifically inhibits sperm-oolemma fusion but not binding
}

\author{
M. Mat Noor ${ }^{1 *}$ and H. D. M. Moore ${ }^{1,2+}$ \\ Departments of ${ }^{\prime}$ Molecular Biology and Biotechnology and ${ }^{2}$ Obstetrics and Gynaecology, University of Shefficld, \\ Sheffield $S 102 U H, U K$
}

\begin{abstract}
Balb/c mice were immunized with purified hamster sperm heads for induction of antisera and the production of monoclonal antibodies that recognize preferentially the equatorial segment. Twenty-six hybridoma clones secreted monoclonal antibodies with strong affinity for spermatozoa. The supernatants of 16 clones contained antibodies against the equatorial segment, of which 11 were specific to this region. Five supernatants (M1-M5) containing antibodies that bind to various regions of the sperm head were selected and assessed for the ability to inhibit hamster fertilization in vitro using intact and zona-free oocytes. All the supernatants inhibited fertilization compared with the control. However, M1 supernatant specifically inhibited sperm-egg fusion in a concentration-dependent manner, while sperm-oolemma binding and sperm motility remained unaffected. M1 supernatant recognized an epitope that is exclusive to the equatorial segment and expression of this epitope increased after capacitation and the acrosome reaction. Preliminary immunoblot analysis indicated that M1 monoclonal antibody recognized two protein bands of 37.5 and $34.0 \mathrm{kDa}$.
\end{abstract}

\section{Introduction}

After penetrating the outer investments of the oocyte (cumulus mass and zona pellucida), the acrosome-reacted spermatozoon fuses with the egg membrane, the oolemma. This process is essential for the incorporation of the spermatozoon into the egg cytoplasm in vivo (see Moore and Bedford, 1983; Yanagimachi, 1988; 1994) and is crucial for the rapid delivery of a soluble sperm factor for embryo development (Parrington et al., 1996). Ultrastructural studies in the golden hamster first determined that gamete fusion in mammals is initiated by sperm plasma membrane preserved after the acrosome reaction and is restricted to a region of the sperm head called the equatorial segment (Moore and Bedford, 1978; Bedford et al., 1979). This mode of sperm-egg fusion is a distinct departure from that in non-mammalian vertebrates and invertebrates, but occurs in a similar manner in all mammals examined to date, including humans (Sathananthan et al., 1986) and even the marsupial opossum (Taggart et al., 1993).

Common themes have emerged from the study of cell fusion events in biology (White, 1992; Hughson, 1995). It is evident that viral and cellular membrane fusion processes are mediated by a complex of specific integral and peripheral membrane proteins. Many of these proteins contain specific

*Present address: Jabatan Zoologi, Universiti Kebangsaan Malaysia, Fakulti Sains Hayans, 43600 Bangi Selangor, Malaysia.

tCorrespondence address: Department of Molecular Biology and Biotechnology, University of Sheffield, Firth Court, Western Bank, Sheffield S10 2UH, UK.

Received 28 April 1998. fusion domains which, when exposed, cause fusion of lipid components from two opposing bilayers. Exactly how these fusion proteins are activated depends on the cell type. For example, haemagglutinin-mediated fusion of influenza virus is influenced by low pH within an endosome (Bullough et al., 1994). In contrast, HIV-1 viral fusion with T cells is mediated by a seven-transmembrane $G$ protein-coupled receptor named fusin (Feng et al., 1996) which may orientate and expose the fusion peptide of the gp120/41 complex. In mammalian gametes, the morphology of fusion is well documented but the biochemical interactions are poorly understood.

Only acrosome-reacted spermatozoa normally reach the perivitelline space of intact oocytes to interact with the oolemma (Moore and Bedford, 1983) and spermatozoa must undergo an acrosome reaction to be capable of fusing naturally with zona-free oocytes (Yanagimachi, 1988) or artificially with erythrocytes (Holt and Dott, 1980). Thus, completion of the acrosome reaction results in a functional sperm fusion protein on the plasmalemma overlying the apical equatorial segment. Studies with liposomes support the hypothesis that the equatorial segment is the sole fusogenic domain of the spermatozoon (Arts et al., 1993). Liposomes only fuse with the equatorial region (after the acrosome reaction) and fail to diffuse to other membrane domains, indicating the presence of a lipid diffusion barrier that prevents lateral movement of intramembranous molecules.

Several putative fusion proteins have been reported for mammalian spermatozoa (Saling et al., 1985; Okabe, et al., 1990; Allen and Green, 1995; Toshimori, et al., 1998) of which 
only one, fertilin, has been well characterized (formerly PH30; Primakoff et al., 1987). This sperm antigen was identified by a monoclonal antibody, designated $\mathrm{PH}-30$, that inhibits sperm-egg fusion in the guinea-pig (Primakoff et al., 1987). Support for a fusogenic role for fertilin came mostly from investigations in which the gene encoding this protein was cloned (Blobel et al., 1992). Fertilin shares similarity with certain viral adhesion proteins, including membrane topology, proteolytic processing from a larger molecule, a disintegrin binding domain and a putative fusogenic domain (Wolfsberg et al., 1993). However, it is doubtful that fertilin is the principal fusion protein because it is not localized to the equatorial segment of spermatozoa. The original study used immunogold labelling with $\mathrm{PH}-30$ monoclonal antibody. Under the electron microscope, fertilin was clearly localized to the post-acrosomal region of acrosome-reacted guinea-pig spermatozoa and there was no labelling at the equatorial segment (Primakoff et al., 1987). Since guinea-pig fertilization is essentially the same as in other mammals (Yanagimachi, 1994), this localization is incompatible with a primary role for fertilin in the fusogenic process. The argument for fertilin as a fusion protein is further disputed by the finding that the human fertilin $\alpha$ gene is non-functional (Jury et al., 1997) and that mice deficient in fertilin $\beta$ produce spermatozoa that are still capable of fusion with the oocyte (Cho et al., 1998). Overall, these results indicate that fertilin is more involved in sperm-egg adhesion than in fusion (see Almeida ct al., 1995).

In view of the conflicting evidence concerning the proposed role for fertilin and its known localization and properties after the acrosome reaction, monoclonal antibodies were used to investigate sperm antigens that may be involved in gamete fusion. Hamsters were used because their oocyte oolemma is receptive to heterologous spermatozoa and shows little species specificity. Hence, the ability of spermatozoa to fuse with the oolemma may more likely represent intrinsic sperm fusogenic capacity than cell recognition (adhesive) ability.

\section{Materials and Methods}

\section{Reagents}

All chemicals were purchased from Sigma Chemicals Ltd (Poole) unless otherwise stated.

\section{Animals}

Balb/c mice and Syrian hamsters (15-20 weeks) were maintained and housed at the University of Sheffield Field Laboratories. Females were superovulated as described by Moore and Hartman (1984). All procedures were carried out in strict accordance with the Animal (Scientific Procedures) Act 1986, and subjected to review by a local ethics committee.

\section{Monoclonal antibody production}

Monoclonal antibodies were produced as outlined by Harlow and Lane (1988). All the procedures for tissue culture were carried out in a horizontal laminar flow hood. Myeloma cells and hybridomas were cultured in $5 \% \mathrm{CO}_{2}$ in air at $37^{\circ} \mathrm{C}$ and $95-100 \%$ humidity (Haraeus Ltd, London). Myeloma cell lines (Sp2) were cultured in a standard medium of RPMI1640 with L-glutamine supplemented with $10 \%(\mathrm{v} / \mathrm{v})$ fetal calf serum (FCS), $1 \%(\mathrm{w} / \mathrm{v})$ sodium pyruvate, and $1 \%(\mathrm{v} / \mathrm{v})$ 10000 iu benzyl penicillin and streptomycin antibiotics $\mathrm{ml}^{-1}$. Hybridoma cells were maintained in complete medium containing $20 \%(\mathrm{v} / \mathrm{v})$ FCS and supplemented with $1 \%(\mathrm{w} / \mathrm{v})$ L-glutamine, $1 \%$ OPI $(1.5 \%(\mathrm{w} / \mathrm{v})$ oxaloacetate, $0.5 \%(\mathrm{w} / \mathrm{v})$ sodium pyruvate), $2000 \mathrm{iu}$ insulin, and $1 \% \mathrm{AH}(0.01 \%(\mathrm{w} / \mathrm{v})$ azaserine, $0.14 \%(\mathrm{w} / \mathrm{v})$ hypoxanthine). HAT (hypoxanthine, aminopterin and thymidine) medium was used for selection of hybridomas. This was complete medium containing $2 \%$ (v/v) $50 \times$ stock solution of hypoxanthine, aminopterin and thymidine. All media were filter sterilized using a $0.2 \mu \mathrm{m}$ Millipore filter and stored at $37^{\circ} \mathrm{C}$ before use.

\section{Preparation of sperm heads and immunization of mice}

Spermatozoa from the cauda epididymidis were collected in minimum essential medium (MEM) as described by Ellis $e t$ al. (1985). The sperm suspension was sonicated (MSE Soniprep 150, setting 14) for $35 \mathrm{~s}$ to separate sperm heads and tails and also to remove the acrosomal cap and expose the inner acrosomal membrane and anterior margin of the equatorial segment. The suspension was filtered through three layers of tissue paper (Kleenex Ltd) to remove sperm tails, and the sperm heads were purified on a discontinuous Percoll density gradient; 90 and $50 \%$ Percoll in MEM for $4 \mathrm{~h}$ at $10000 \mathrm{~g}$. The sperm heads were aspirated as a discrete band close to the bottom of the gradient with the formation of a continuous gradient. An aliquot of each batch of sperm heads was prepared for light and electron microscopy and the preparation was stored at $-20^{\circ} \mathrm{C}$. For immunization, sperm heads were diluted to approximately $10^{8} \mathrm{ml}^{-1}$ and added to an equal volume of Freund's complete adjuvant. Blood samples were taken from the tail vein of female Balb/c mice (12 weeks old) for pre-immune serum. The females were then injected i.m. with approximately $10^{7}$ spermatozoa in $0.1 \mathrm{ml}$ adjuvant. After 2 weeks, the females were injected again with incomplete adjuvant. After a further 6 weeks, animals were given a booster injection of approximately $10^{9}$ spermatozoa $(0.1 \mathrm{ml})$ from the same initial preparation except without adjuvant and in PBS. Five days after the booster injection, a mouse was killed for hybridoma production by standard protocols (Harlow and Lane, 1988) and using polyethylene glycol (PEG 4000, Gibco, Paisley). Potential hybridoma cells $\left(10^{5} \mathrm{ml}^{-1}\right)$ were pipetted into 96 - and 24-well plates, and incubated in $5 \% \mathrm{CO}_{2}$ in air at $37^{\circ} \mathrm{C}$. After 5 days the cells were inspected for hybridoma clones. Half of the growth medium was replenished with fresh complete medium every 4 days for 96-well plates and every 6 days for 24-well plates. Supernatant from wells containing hybridoma cells was tested for specific antibody from about 10 days after fusion.

\section{Screening for antibodies}

Sera from immunized mice and the hybridoma supernatants were screened for antibodies by indirect immuno- 
fluorescence with viable and methanol-fixed hamster spermatozoa at a dilution of 1:50 as described by Ellis et al. (1985). Crossreactivity of positive supernatants was assessed with ejaculated rabbit and human spermatozoa and rat epididymal spermatozoa, washed by centrifugation in PBS, air dried on microscope slides and fixed in methanol. Antibodies were isotyped using a commercial kit (Sigma, Poole) according to the manufacturer's instructions.

\section{Cloning of hybridomas by limiting dilution}

Positive hybridoma cells were cloned by limited dilution in growth factor-conditioned medium in 96-well plates. This was repeated three times. The concentration of the hybrid cells was adjusted to approximately one cell per well for each clone. Supernatants were collected 10-15 days after limiting dilution. The supernatants were tested by indirect immunofluorescence to verify that a specific clone had been isolated. The cell suspensions were stored in cryotubes in a polysterene cooling container at $-70^{\circ} \mathrm{C}$. The following day, the cryotubes were transferred to liquid nitrogen at $-196^{\circ} \mathrm{C}$.

\section{In vitro fertilization}

Investigation of the effects of monoclonal antibodies (hybridoma supernatants) on in vitro fertilization using intact and zona-free oocytes was conducted according to Moore and Hartman (1984) with minor modifications. Fertilization was carried out in $0.1 \mathrm{ml}$ drops of Biggers, Whitten and Whittingham (BWW) medium under mineral oil (Biggers et al., 1971). The medium was supplemented with $0.04 \%(\mathrm{w} / \mathrm{v}) \mathrm{BSA}$ and filter sterilized using a $0.2 \mu \mathrm{m}$ filter. The osmolarity of the medium was 308 mosmol, pH 7.2, after equilibration overnight in a humidified incubator in $5 \% \mathrm{CO}_{2}$ in air at $37^{\circ} \mathrm{C}$. Sperm suspensions $\left(5 \times 10^{6}\right.$ spermatozoa $\left.\mathrm{ml}^{-1}\right)$ were incubated in $5 \% \mathrm{CO}_{2}$ in air at $37^{\circ} \mathrm{C}$ for $3 \mathrm{~h}$ to promote capacitation as described by Bavister (1989). After $3 \mathrm{~h}$, hybridoma culture supernatant containing sperm-specific monoclonal antibody or myeloma culture supernatant $\left(0.75-1.0 \mu \mathrm{g} \mathrm{ml}^{-1}\right)$ was added to the individual drops at a 1:10 dilution or as specified and the incubation was continued for $30 \mathrm{~min}$. Washed oocytes from superovulated females (Moore and Hartman, 1984) were transferred directly to the preincubated sperm preparation (containing antibody) or were treated with $0.1 \%(\mathrm{w} / \mathrm{v})$ trypsin to dissolve the zona pellucida and washed four times in fresh medium before being placed in the drops. Approximately 15-20 oocytes were placed into $0.1 \mathrm{ml}$ pretreated spermatozoa at a concentration of $10^{6}$ spermatozoa $\mathrm{ml}^{-1}$. Oocytes were assessed after $16 \mathrm{~h}$ for signs of fertilization as described by Aitken (1986).

Immunofluorescent localization of M1 antigen on spermatozoa bound to zona-free oocytes in the presence of M1 monoclonal antibody was achieved by gently washing oocytes by three transfers in drops of BWW medium and incubation for $1 \mathrm{~h}$ in medium containing fluoresceinconjugated goat anti-mouse IgG (1:100 dilution). Oocytes were washed and then examined on paraffin wax spot slides by epifluorescent microscopy.

\section{Electron microscopic localization of $M 1$ antigen}

Preliminary ultrastructural localization of M1 antigen was performed on capacitated hamster spermatozoa after $3 \mathrm{~h}$ incubation as described above. Sperm suspensions were incubated with monoclonal antibody M1 hybridoma medium at $37^{\circ} \mathrm{C}$ in $5 \% \mathrm{CO}_{2}$ in air for $1 \mathrm{~h}$. The spermatozoa were washed twice by centrifugation at $1000 \mathrm{~g}$ for $5 \mathrm{~min}$ and resuspended in goat anti-mouse $\operatorname{IgG}$ gold conjugate $(10 \mathrm{~nm})$ diluted 1:10 in medium and incubated for $1 \mathrm{~h}$. The spermatozoa were washed by centrifugation and fixed in $2.5 \%(\mathrm{v} / \mathrm{v})$ glutaraldehyde in $0.2 \mathrm{~mol}$ cacodylate buffer $\mathrm{l}^{-1}$ for $2 \mathrm{~h}$ at $4^{\circ} \mathrm{C}$ before preparation for transmission electron microscopy. Ultrathin sections were examined in a Philips CM10 electron microscope at an accelerated voltage of $80 \mathrm{kV}$.

\section{Immunoblotting}

Preliminary characterization of M1 antigen was achieved by solubilization of spermatozoa and sperm head samples $\left(10^{8}\right.$ spermatozoa $\left.\mathrm{ml}^{-1}\right)$ with $1 \%(\mathrm{w} / \mathrm{v})$ sodium lauryl sulphate for $15 \mathrm{~min}$, centrifugation at $5000 \mathrm{~g}$ for $5 \mathrm{~min}$ and recovery of supernatant by aspiration. Protease inhibitors were not added as it was assumed enzyme activity would be minimal in detergent. Extracts were then subjected to SDS-PAGE and transferred to nitrocellulose membrane for protein staining or immunoblotting with specific monoclonal antibody as described by Ellis et al. (1985).

Immunodot blotting was performed using hamster testis, epididymis, lung, kidney, spleen, brain and liver to determine tissue distribution of M1 antigen. Tissues were removed immediately after death and snap frozen in liquid nitrogen. The tissues were thawed and homogenized in PBS containing $2 \mathrm{mmol}$ phenylmethanesulphonyl-fluoride (PMSF) $\mathrm{I}^{-1}$ and solubilized in SDS reducing buffer. The amount of tissue extract was determined using a bicinchoninic acid protein assay kit (Pierce Chemicals, Rockford, IL). Ten micrograms of each protein sample was blotted onto nitrocellulose membrane and processed as described above.

\section{Results}

\section{Immunization and production of monoclonal antibodies}

The procedure for isolation of hamster sperm heads was very effective. Examination of the preparation with phasecontrast microscopy revealed that the amount of non-head organelles was less than $0.1 \%$ (Fig. 1). Electron microscopy confirmed that sperm heads were free of their acrosomal caps and flagella and that little extraneous sperm material was present except for some membrane material. The equatorial segment remained intact in most sperm heads, although the plasma membrane was missing in some cases. Small particles of Percoll were bound to the sperm heads (Fig. 2).

Sera from immunized mice showed reactivity to methanol-fixed hamster spermatozoa and crossreactivity to 


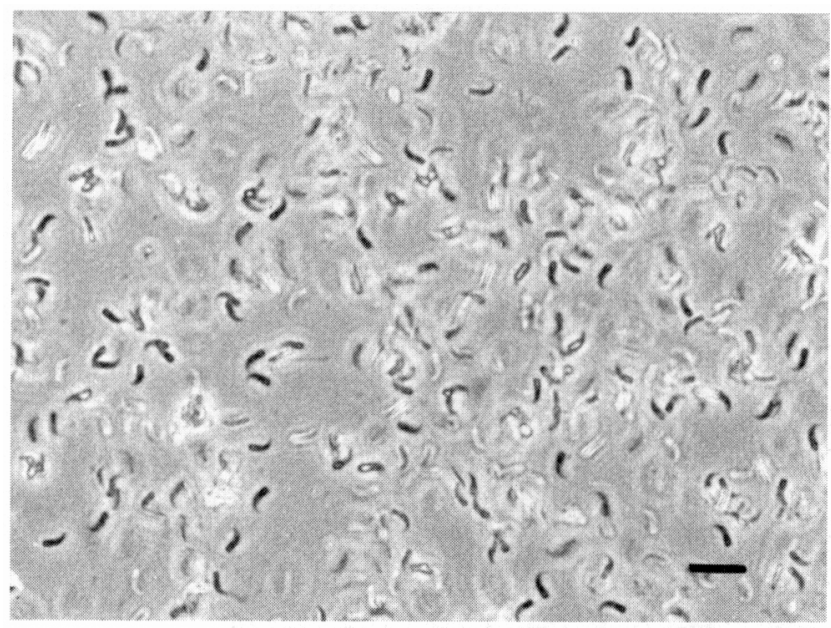

Fig. 1. Phase-contrast light micrograph of purified hamster sperm heads recovered from a Percoll density gradient. Scale bar represents $50 \mu \mathrm{m}$.

methanol-fixed spermatozoa from human, rat and rabbit, as detected by immunofluorescence. In each case, antibodies were localized specifically to the head region of fixed spermatozoa and always to the equatorial segment. There was strong immunofluorescence to the acrosomal and postacrosomal region with intact hamster spermatozoa. In cases in which the acrosome cap had been lost, antibody was detected on the equatorial segment and post-acrosomal region. In rat, rabbit and human spermatozoa, immunofluorescence was restricted to the entire acrosome of intact cells and to the equatorial segment when the anterior acrosome was missing.

After initial screening protocols, two splenocyte-myeloma fusions yielded 56 hybridoma clones secreting anti-sperm antibody. Of these, 26 supernatants had high affinity for spermatozoa, as assessed by immunofluorescent localization, and showed five different patterns of staining (see Table 1). Sixteen supernatants contained antibodies that recognized the equatorial segment, of which 11 were specific to this region. One hybridoma that secreted antibody for each localization pattern was selected and cloned fully for monoclonal antibody production. Immunofluorescent localization of the binding of these monoclonal antibodies (designated M1-M5) with viable spermatozoa from the cauda epididymidis incubated in BWW medium is shown (Fig. 3). M1 localized to the equatorial segment, M2 to the neck region, M3 to the post-acrosomal region, M4 to the anterior acrosome and equatorial segment, and M5 to the equatorial segment and the 'zipper' region (see Eddy

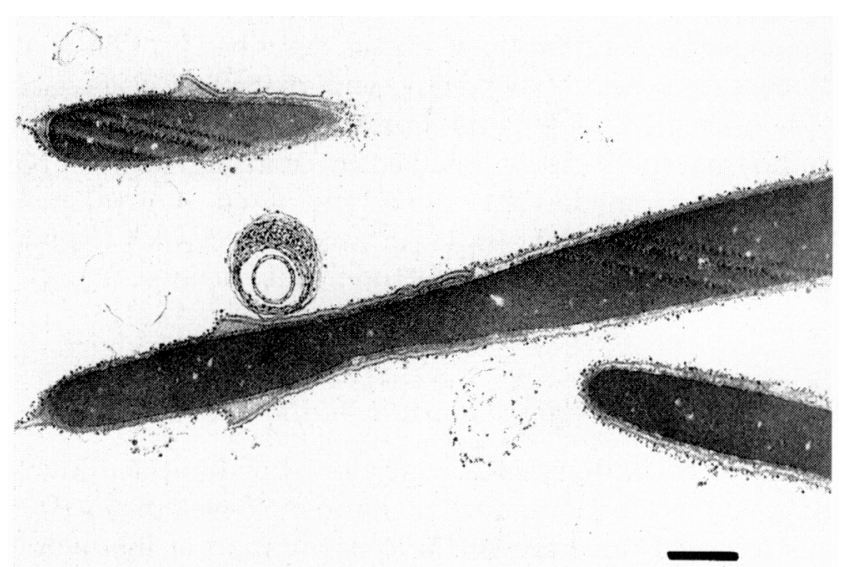

Fig. 2. Transmission electron micrograph of purified hamster sperm heads recovered from a Percoll density gradient. The plasma and acrosomal membranes have been separated from the sperm heads although some membranous vesicles remain. Percoll particles are bound to the spermatozoa. Scale bar represents $2 \mu \mathrm{m}$.

and O'Brien, 1994). Fluorescence was not observed in the absence of primary antibody, or in the presence of preimmune serum or supernatant of non-immunoglobulin secreting cell lines. Isotyping testing indicated that all the monoclonal antibodies were IgG1 subclass, except for M1 which was IgG2a.

\section{Effect of monoclonal antibody on in vitro fertilization}

During incubation in vitro, hamster spermatozoa agglutinated spontaneously, but subsequently dispersed and became freely motile as capacitation proceeded. After $3 \mathrm{~h}$, a proportion of spermatozoa showed hyperactivated motility. The addition of M3 supernatant resulted in sperm agglutination, but the other preparations had no detectable effect on sperm motility. The effect of monoclonal antibody (in culture supernatant) on fertilization in vitro with intact hamster oocytes is summarized (Table 2). The results indicate that all the hybridoma supernatants (M1-M5) inhibited fertilization compared with the control myeloma supernatant, but this was most significant $(P \leq 0.005)$ for M1, M3 and M5. The supernatants did not have any obvious effect on sperm motility at the dilutions used, with the exception of M3 supernatant which caused sperm agglutination. Spermatozoa were frequently observed in the perivitelline space of oocytes incubated with M1 and M5

Table 1. Hybridoma clones generating sperm-specific antibodies after two myeloma-spleenocyte fusions

\begin{tabular}{lcccccc}
\hline Fusion & Positive clones & \multicolumn{5}{c}{ Hybridoma producing antibodies to various regions of the sperm head } \\
\hline A & 22 & 7 & 5 & 3 & 7 & - \\
B & 4 & 3 & - & - & - & 1 \\
\hline
\end{tabular}



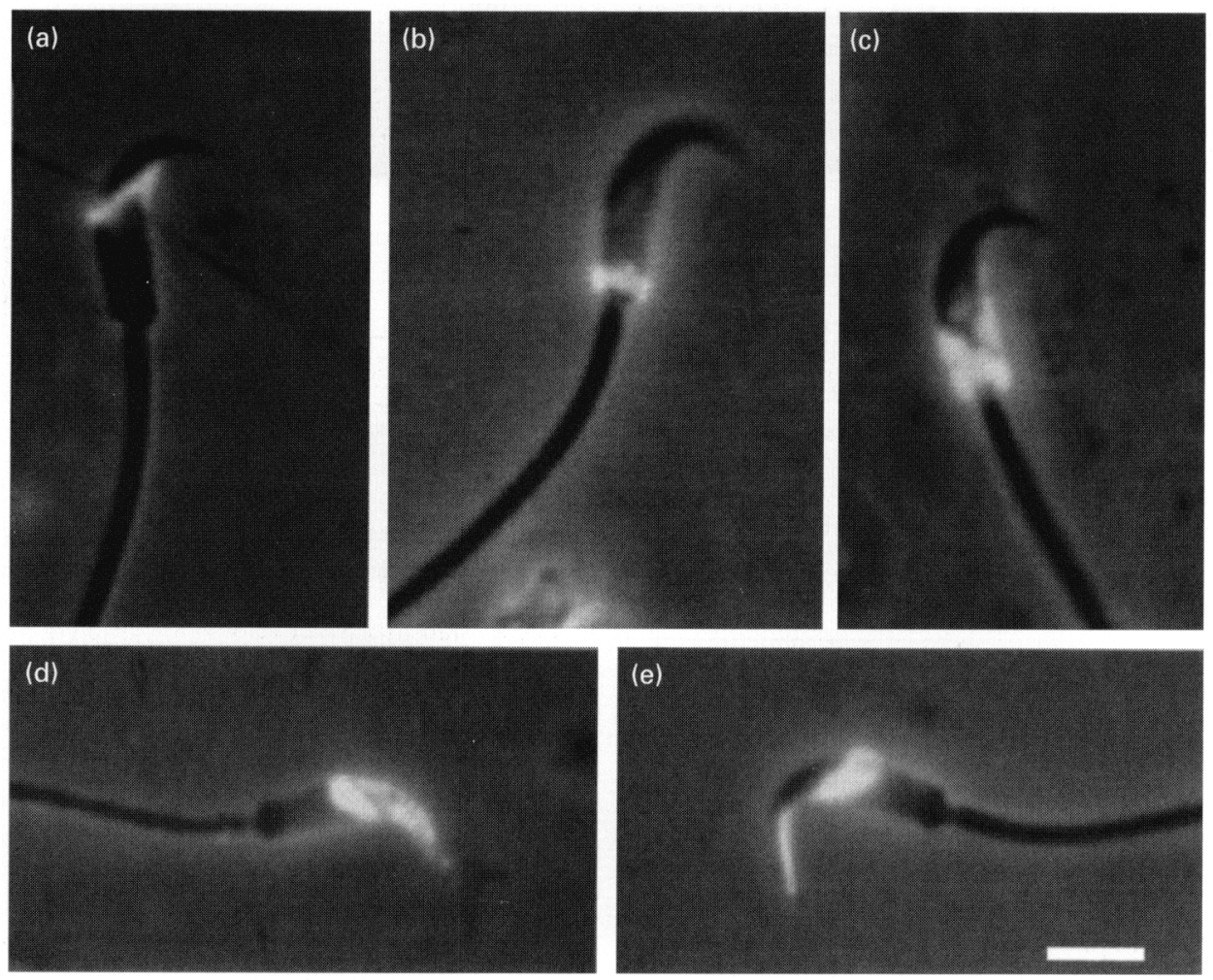

Fig. 3. Indirect immunofluorescent staining patterns for hobridoma supernatants on viable hamster spermatozod using phase-contrast and UV epifluorescent microscopy. (a) M1, (b) M2, (c) M3, (d) M. and (o) M5. Scale bar represents $5 \mu \mathrm{m}$.

antibodies, but these were not fertilized. The effect of hybridoma supernatant on sperm penetration of zona-free oocytes is summarized (Table 3). M1, M3 and M5 supernatants significantly inhibited $(P \leq 0.005)$ sperm-eggr fusion. The mean number of spermatozoa bound (but not fused) to zona-free oocytes when spermatozoa were preincubated with control supernatant was 9.1 \pm 7.2 . When spermatozoa were preincubated with M1 supernatant, a similar mean number of spermatozoa bound to oocytes $(8.8$ \pm 6.1 ). In contrast, the mean number of spermatozoa bound to oocytes in the presence of M2 and M5 supernatants was $3.0 \pm 22$ and for M3 was $0.4 \pm 0.3$. These observations indicate that the inhibition of sperm-egg fusion in the presence of M1 antibody supernatant was due to inhibition of sperm-oolemma fusion rather than sperm-oolemma binding. Therefore M1 monoclonal antibody was investigated further. A titration curve for inhibition of sperm-egg fusion by M1 supernatant was determined (Fig. 4). At a sperm concentration of $10^{n} \mathrm{ml}$ ', maximal inhibition of sperm-egg fusion was achieved with $1: 5$ and 1:10 dilution $(P<0.005)$. However, there was significant inhibition $(P<0.05)$ of sperm-egg fusion at a dilution of $1: 40$ compared with control supernatant $\left(86^{\circ} \circ\right.$ spermegg fusion at the same dilution of supermatant). At each dilution of hybridoma supernatant, there was no difference in the number of spermatoma initially bound to oocytes $(12.8 \pm 6.1)$.
Characterization of immunofluorescent localization of $M 1$ monodonal antibdy during capacitation and sperm-e'se interaction

In non-capacitated viable spermatozoa, a faint narrow band was visualized at the apical margin of the equatorial region (Fig. 5a). When spermatozoa were examined after capacitation in iitro, there was an increasing proportion of viable (motile) spermatozoa exhibiting greater localization of antibody over the equatorial segment, as assessed by fluorescent intensity and area (Fig. 5b). At high magnification under phase-contrast microscopy, these motile spermatozon were also observed to have undergone the acrosome reaction. In three experiments, the development of antigen expression on spermatozoa under in intro fertilization capacitating conditions was quantified. Assessment of immunolocalization of M1 in 200 spermatozoa atter $1 \mathrm{~h}$ of incubation revealed that $88 \pm 9 \%$ of cells had fluorescent staining on only the apical margin of the equatorial segment. After $3 \mathrm{~h}$, this proportion decreased to $32 \pm 15 \%$ and the remaining cells showed fluorescence all over the equatorial segment, although often the distribution was patchy. In methanol-fixed spematozoa, M1 monoclonal antibody localized intensely throughout the equatorial segment by indirect immumofluorescence (Figr. 5c).

Spermatozoa bound to zona-free hamster oocytes in the presence of M1 monoclonal antibody showed Ml antigen at the equatorial region of the sperm head, as detected by 
Table 2. Effect of hybridoma supernatants (M1-M5) on hamster fertilization in vitro

\begin{tabular}{lcc}
\hline Supernatant & Oocytes examined & Oocytes fertilized (\%) \\
\hline Myeloma control & 90 & $52(87)$ \\
M1 & 26 & $2(8)^{*}$ \\
M2 & 26 & $13(52)$ \\
M3 & & $3(10)^{*}$ \\
M4 & 29 & $5(21)$ \\
M5 & 24 & $4(16)^{*}$ \\
\hline
\end{tabular}

*Significantly different from control $(P \leq 0.005)$.

'Sperm agglutination.

Table 3. Effect of hybridoma supernatants (M1-M5) on hamster sperm penetration of zona-free hamster oocytes in vitro

\begin{tabular}{lcc}
\hline Supernatant & Oocytes examined & Oocytes fertilized (\%) \\
\hline Myeloma control & 75 & $70(93)$ \\
M1 & 70 & $8(11)^{*}$ \\
M2 & 58 & $33(57)$ \\
M3 & & $0(0)^{*}$ \\
M4 & 11 & $26(68)$ \\
M5 & 38 & $19(31)^{*}$ \\
\hline
\end{tabular}

*Significantly different from control $(P \leq 0.005)$.

'Sperm agglutination.

immunofluorescence (Fig. 6a,b). The intensity of staining varied, although most spermatozoa showed some immunofluorescence when examined across the focal plane.

\section{Electron microscopic localization of M1 antigen}

Immunogold label was not present on intact spermatozoa. On spermatozoa that had undergone the acrosome reaction, immunogold particles were localized predominantly on the plasma membrane overlying the equatorial region (Fig. 7a,b). A few particles were located on vesiculated membranes of anterior acrosome (Fig. 7a). Immunogold label was not present elsewhere on the spermatozoa and was absent from control samples. Analysis of a random sample of 100 sections of acrosome-reacted spermatozoa for gold particle localization showed that there were $26 \pm 12$ particles on the equatorial segment, $6 \pm 4$ particles on associated membrane vesicles of the anterior acrosome, and $0.5 \pm 2.0$ particles at other sites, or on control samples.

\section{Preliminary biochemical characterization of $M 1$ antigen}

Protein from intact spermatozoa, Percoll-purified sperm heads, or $1 \%(\mathrm{w} / \mathrm{v})$ sodium lauryl sulphate extraction of sperm heads was subjected to SDS-PAGE and immobilized on nitrocellulose membrane. A number of protein bands

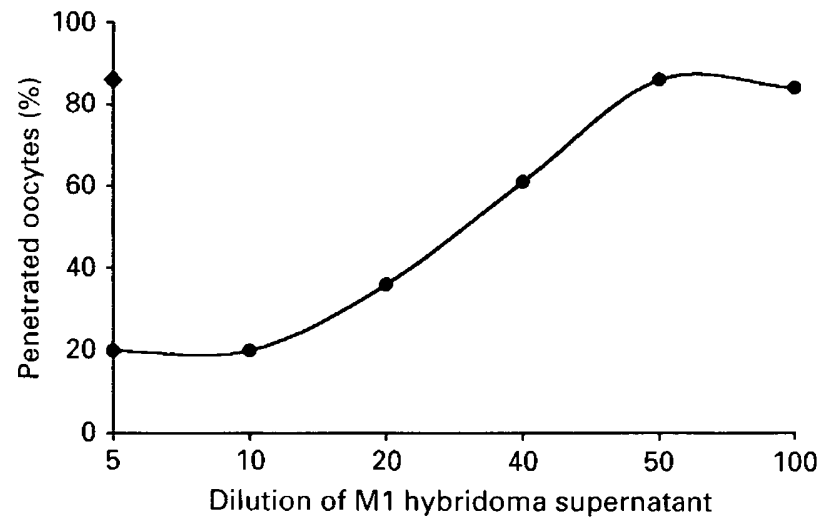

Fig. 4. Titration curve for M1 supernatant inhibition of hamster sperm-egg fusion in vitro. $\downarrow$, mean control value.

were revealed by Coomassie blue staining, including major bands at 37.5 and $26.0 \mathrm{kDa}$ (Fig. 8). Immunoblotting with M1 antibody recognized two bands at 37.5 and $34.0 \mathrm{kDa}$ in the purified preparations (Fig. 8). Immunodot blots of various tissue samples indicated that M1 antigen was only present in the epididymis and testis.

\section{Discussion}

The initial aim of this study was to derive monoclonal antibodies that recognized antigens of the equatorial segment. Intact spermatozoa have been used to immunize mice, but this has often led to monoclonal antibodies that recognize the apical region of the sperm acrosome and the flagellum, rather than the equatorial segment (see Moore and Hartman, 1984; Eddy and O'Brien, 1994). This may be because acrosome and tail components are more antigenic than other sperm components. The flagellum represents over $90 \%(\mathrm{v} / \mathrm{v})$ of the hamster spermatozoon (Yanagimachi, 1994). In the present study, brief sonication of spermatozoa resulted in dissociation of the acrosomal cap and flagellum from the sperm head, which could then be purified by Percoll separation. In this preparation, the equatorial segment was more exposed. The anterior acrosome was absent and plasma membrane was missing from some cells, thereby increasing the possibility of obtaining antibodies to this region. Each antiserum recognized the hamster sperm equatorial segment, but also bound to the anterior acrosome. Since the purpose of the immunization was to enhance the production of antibodies to the equatorial segment, the specificities of the antisera were considered satisfactory, particularly as antibodies to the flagellum had not been generated preferentially. Immunofluorescent localization indicated that antisera crossreacted with spermatozoa from several mammalian species, indicating that some sperm epitopes may be conserved between species (Eddy and O'Brien, 1994).

The selection of hybridomas for final cloning was based on the pattern of immunofluorescence. It was decided that a variety of monoclonal antibodies to the sperm head should be produced so that valid comparisons could be made, but 

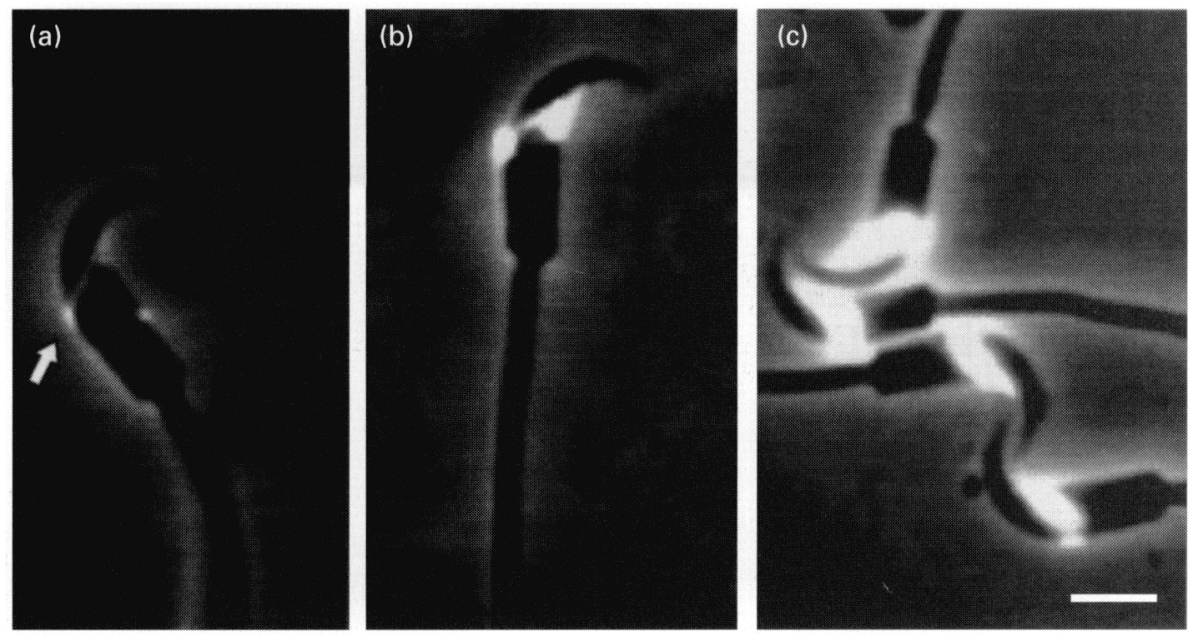

Fig. 5. Indirect immunofluorescent localization with M1 hybridoma supernatant on hamster spermatozoa using phase-contrast and UV epifluorescent microscopy. (a) Non-capacitated viable spermatozoa show staining at the apical margin of the equatorial region. (b) Fully capacitated viable spermatozoa show intense fluorescence over the entire equatorial region. (c) Methanol-fixed spermatozoa show bright fluorescence over the equatorial region. Sale bar represents $5 \mu \mathrm{m}$.
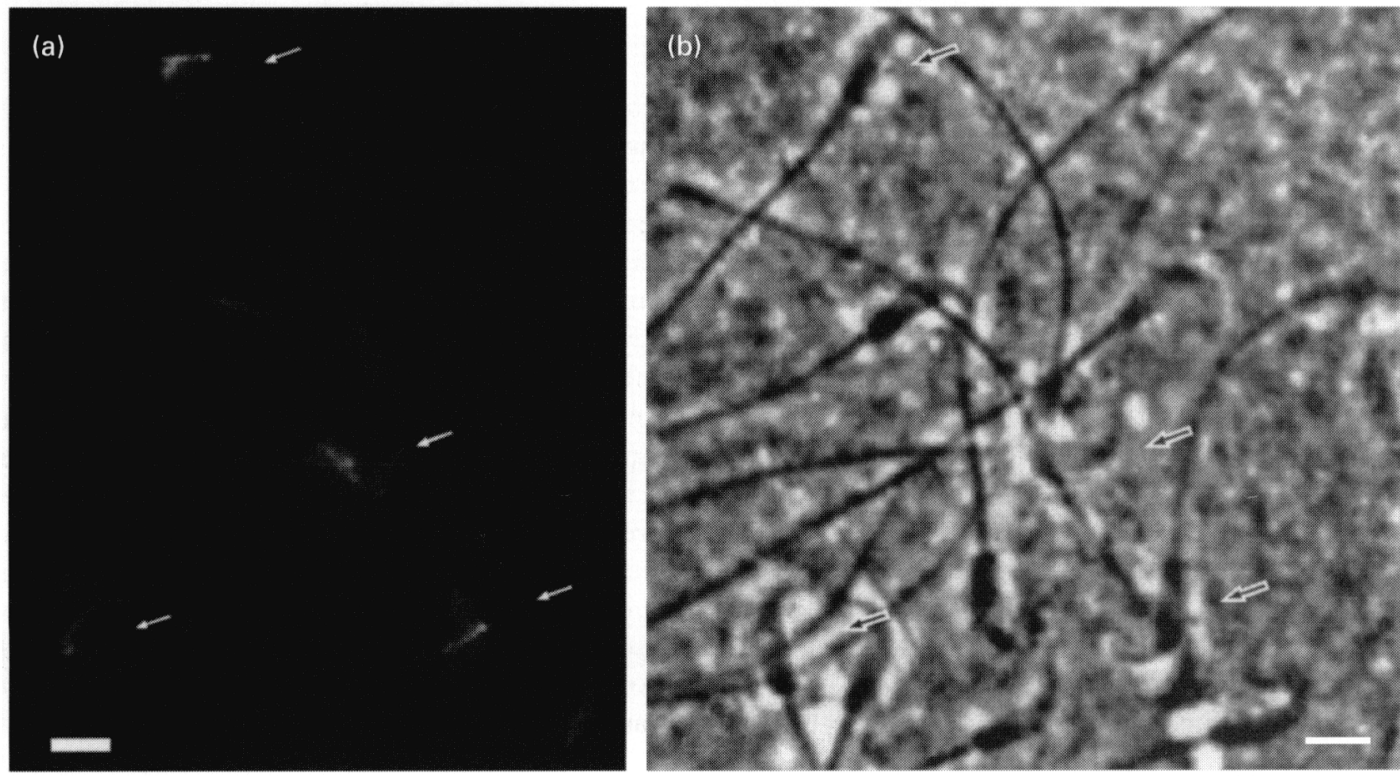

Fig. 6. Indirect immunofluorescent localization of M1 antigen on hamster spermatozos bound to zona-free oocytes in vitro. Corresponding (a) epifluorescent and (b) phase-contrast micrographs. M1 antigen localized to the equatorial region (arrows) of spermatozoa bound to the surface of the oocyte. Scale bars represent $8 \mu \mathrm{m}$.

with a principal objective of identifying antigens involved in sperm-egg fusion. Hybridoma supernatant was added to sperm suspensions at the end of a $3 \mathrm{~h}$ incubation period when capacitation was considered complete and a high proportion of spermatozoa had hyperactivated motility. On the basis of studies indicating that sperm-egg fusion can only occur after sperm capacitation and the acrosome reaction (see Yanagimachi, 1994), it was surmised that at this stage pertinent antigens would be exposed (or modified). A primary screen with zona-intact oocytes revealed that M1, M3 and M5 antibody supernatants markedly inhibited fertilization. M1 and M5 supernatants had no effect on sperm motility, but M3 caused considerable sperm agglutination.

M3 and M5 supernatant caused a reduction in sperm binding to the oolemma compared with the control; this was not observed with M1 supernatant. $A$ dose-dependent curve of M1 antibody inhibition of sperm-egr fusion was obtained (with no change in sperm-eggr binding) that was consistent 


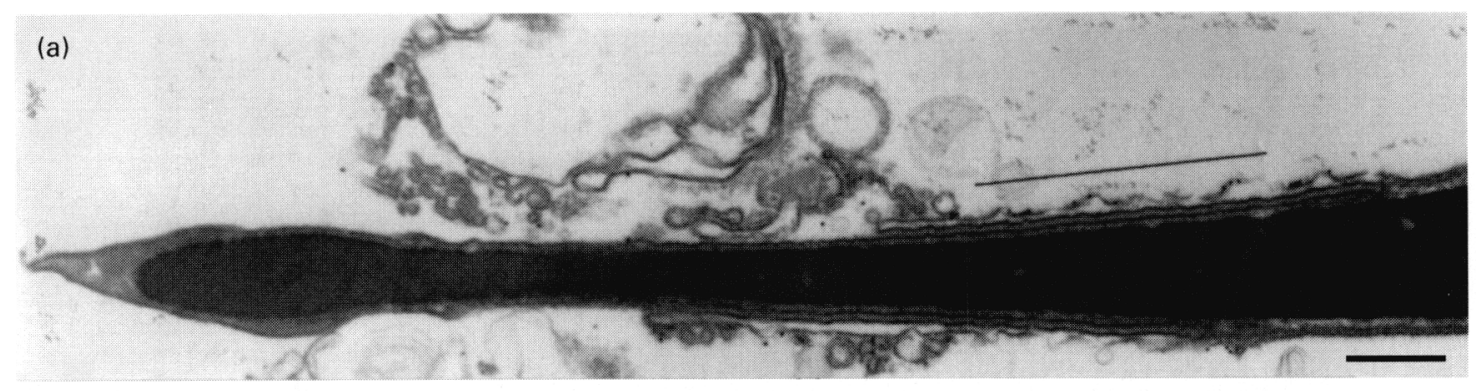

(b)

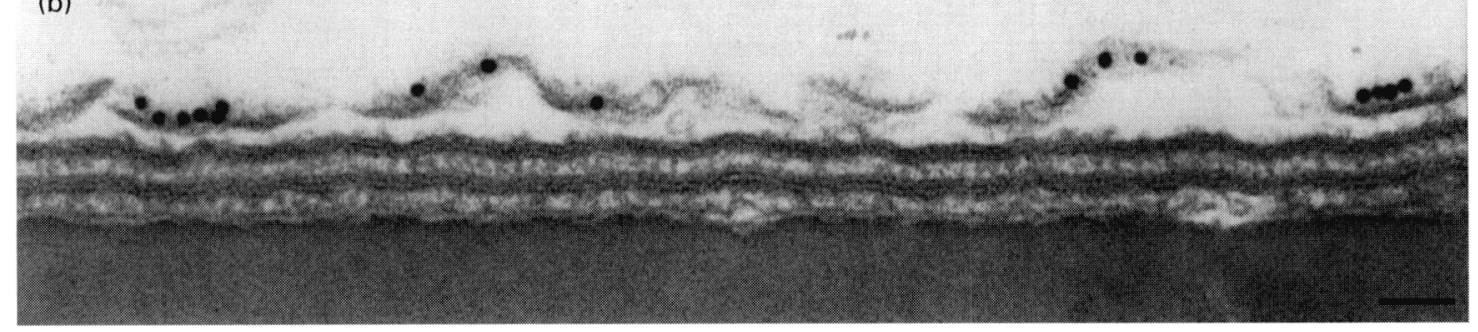

Fig. 7. Immunogold localization of M1 antigen on hamster spermatozoa. (a) An acrosome-reacted spermatozoon with associated membranes of the anterior acrosome. The membranes over the equatorial region are intact. (b) The region below the line in (a) at higher magnification. Particles were localized predominantly on the plasma membrane overlying the equatorial segment. No particles were present on intact spermatozoa. Scale bars represent (a) $0.5 \mu \mathrm{m}$ and (b) $0.1 \mu \mathrm{m}$.

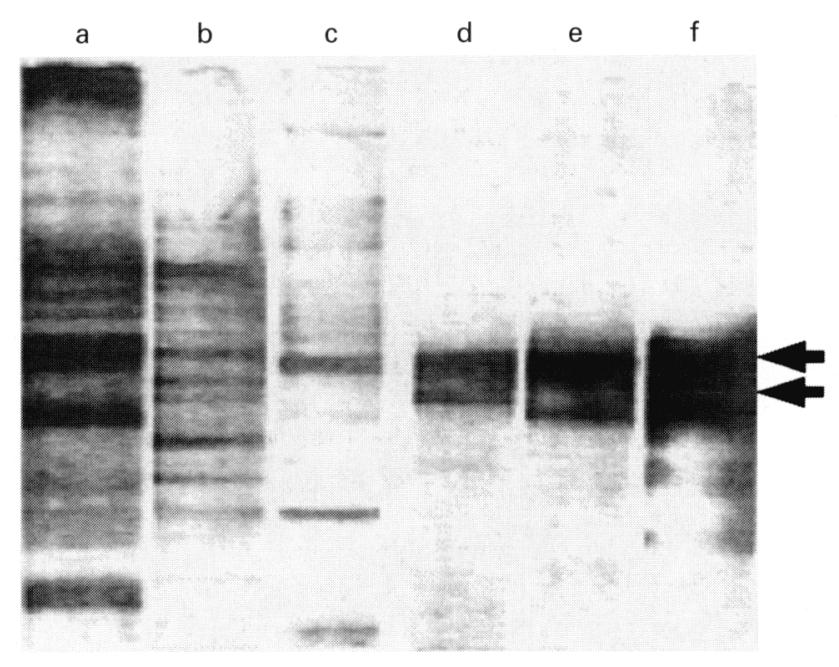

Fig. 8. Detection of M1 antigen on hamster spermatozoa after SDSPAGE and immobilization of protein on nitrocellulose membrane. Lanes a-c are stained with Coomassie blue: a, intact spermatozoa; b, Percoll-purified sperm head; c, SDS extract of Percoll-purified sperm heads. Lanes d-e are the corresponding preparations to those in lanes a-c, immunoblotted with M1 hybridoma supernatant. Main protein bands (arrows) are at 37.5 and $34.0 \mathrm{kDa}$.

with interference with a receptor-mediated process (see Wassarman, 1990). M1 antigen clearly localized to the equatorial segment of spermatozoa bound to the oolemma. Thus, the antibody may inhibit sperm-oolemma fusion rather than sperm-oolemma binding. Alternatively, M1 antibody may prevent sperm head decondensation after gamete fusion. The zona-free egg penetration test relies on detecting swollen sperm heads in the vitellus (Aitken, 1986). Therefore, using standard protocols it is not possible to distinguish between antibody inhibition of sperm-egg fusion or antibody inhibition of sperm head decondensation after fusion. Further investigations using Hoescht 33342stained spermatozoa (Green, 1993) may resolve this problem.

Preliminary ultrastructural localization of M1 using a preembedding immunogold protocol indicated that M1 antigen was localized to plasma membrane overlying the equatorial segment after the acrosome reaction, but was absent from the intact cells. Immunofluorescent staining of live intact and acrosome-reacted spermatozoa produced similar results, with the exception that on intact spermatozoa, immunogold particles were not detected at the apical margin of the equatorial segment, while immunofluorescent localization showed faint staining at this site. Although immunogold binding was not intense, it was highly specific and very few particles were observed away from the equatorial segment plasma membrane or on associated acrosomal membrane vesicles. The intensity of gold particle binding probably reflects the stringency of the washing procedures rather than the amount of antigen present. Gold particles on the equatorial segment (but not elsewhere) were often in small clusters, indicating aggregation of antigen in the membrane.

Exactly how M1 is presented on the plasma membrane overlying the equatorial segment remains to be determined. When sperm membranes were permeabilized by methanol fixation, M1 antigen was localized to the entire equatorial segment, indicating that the primary location of the antigen is intracellular. Ultrastructural observations with disrupted cells also indicate antigen localization to a site between the outer acrosomal and plasma membrane (M. Mat Noor and H. D. M. Moore, unpublished). Allen and Green (1996) 
proposed that novel antigens or epitopes are expressed on the surface of the equatorial segment after the acrosome reaction through the modification of existing antigens by released acrosomal enzymes or by translocation of antigens from an intra-acrosomal site. Neither of these proposals is supported by the preliminary observations of the present study. M1 epitope is not located in the anterior acrosome before the acrosome reaction and does not obviously emanate from acrosomal matrix material after the acrosome reaction. Therefore, a direct translocation from the anterior acrosome is unlikely. The principal location of M1 before the acrosome reaction appears to be between the outer acrosomal and plasma membrane of the equatorial segment. During the acrosome reaction, membrane fusion occurs between the plasma membrane and the outer acrosomal membrane at the anterior margin of the equatorial segment. It is possible that M1 diffuses from its intracellular site during membrane fusion. Since substantial membrane remodelling may occur with the onset of membrane fusion, an alternative proposal is that the antigen is translocated directly across the plasma membrane overlying the equatorial segment after the acrosome reaction.

The characteristics of M1 antigen are similar to those reported for several other putative fusion proteins. Saling $e t$ al. (1985) reported that in mouse spermatozoa, M29 monoclonal antibody inhibited sperm-egg fusion, as detected by sperm head decondensation, but not sperm-egg adhesion, and recognized a determinant of $40 \mathrm{kDa}$. Antigen was localized to the equatorial segment of mouse acrosomereacted spermatozoa. Toshimori et al. (1998) reported that MN9 monoclonal antibody inhibited mouse sperm-oocyte fusion and bound to an antigenic complex (designated 'equatorin') in the equatorial segment with a molecular mass of $38-48 \mathrm{kDa}$. In guinea-pig spermatozoa, G11 and M13 monoclonal antibodies inhibited sperm-egg fusion in a heterologous assay with zona-free hamster oocytes and recognized a $34 \mathrm{kDa}$ protein present on the plasmalemma of the equatorial segment after the acrosome reaction (Allen and Green, 1995). Further ultrastructural investigations are in progress to investigate the precise expression of $\mathrm{M} 1$ in relation to the acrosome reaction and sperm-egg fusion.

Mahanem Mat Noor was supported by the Malaysian Government.

\section{References}

Aitken RJ (1986) The zona-free hamster oocyte penetration test and the diagnosis of male fertility International journal of Andrology Supplement 6 197-199

Allen CA and Green DPL (1995) Monoclonal antibodies which recognize equatorial segment epitopes presented de novo following the A23187-induced acrosome reaction of guinea-pig sperm Journal of Cell Science 108 767-777

Allen CA and Green DPL (1996) The mammalian acrosome reaction: gateway to sperm fusion with the oocyte? Bioessays 19 241-247

Almeida E, Huovila A-P, Sutherland AE, Stephens LE, Calarco PG, Shaw LM, Mercurio A, Sonnenberg A, Primakoff P, Myles DG and White J (1995) Mouse egg integrin $\alpha 6 \beta 1$ functions as a sperm receptor Cell 81 1095-1104

Arts EG, Kuiken J, Jager S and Hoekstra D (1993) Fusion of artifical membranes with mammalian spermatozoa. Specific involvement of the equatorial segment after the acrosome reaction European Journal of Biochemistry 217 1001-1009
Bedford JM, Moore HDM and Frankin LE (1979) Significance of the equatorial segment of the acrosome of the spermatozoa in eutherian mammals Experimental Cell Research 119 119-126

Biggers JD, Whitten WK and Whittingham D (1971) The culture of mouse embryos in vitro. In Methods in Mammalian Embryology pp 86-116 Ed. JC Daniel. Freeman, San Francisco, CA

Blobel CP, Wolfsberg TG, Turck CW, Myles DG, Primakoff $P$ and White JM (1992) A potential fusion peptide and an integrin ligand domain in a protein active in sperm-egg fusion Nature 356 248-252

Bullough PA, Hughson FM, Skehel JJ and Wiley DC (1994) Structure of influenza haemagglutinin at the $\mathrm{pH}$ of membrane fusion Nature 371 37-43

Cho C, $O^{\prime}$ Dell Bunch D, Faure J-E, Goulding EH, Eddy EM, Primakoff $P$ and Myles DG (1998) Fertilization defects in sperm from mice lacking fertilin $\beta$ Science 281 1857-1859

Eddy EM and O'Brien DA (1994) The spermatozoon. In The Physiology of Reproduction Eds E Knobil and E Neill pp 29-77. Raven Press, New York

Ellis DH, Hartman TD and Moore HDM (1985) Maturation and function of the hamster spermatozoon probed with monoclonal antibodies Journal of Reproductive Immunology 7 299-314

Feng Y, Broder CC, Kennedy PE and Berger EA (1996) HIV-1 entry cofactor: functional cDNA cloning of a seven transmembrane $G$ protein-coupled receptor Science 272 872-877

Green DPL (1993) Comparison of Hoechst 33342 and propidium iodide as fluorescent markers for sperm fusion with hamster oocytes fournal of Reproduction and Fertility 96 581-591

Harlow E and Lane D (1988) Antibodies. A Laboratory Manual Cold Spring Harbor Laboratory Press, Cold Spring Harbor

Holt WV and Dott HM (1980) Chemically induced fusion between ram spermatozoa and avian erythrocytes; an ultrastructural study journal of Ultrastructural Research 71311-320

Hughson FM (1995) Structural characterization of viral fusion proteins Current Biology 5 265-274

Jury JA, Frayne J and Hall L (1997) The human fertilin alpha gene is nonfunctional: implications for its proposed role in fertilization Biochemical Journal 321 577-581

Moore HDM and Bedford JM (1978) Ultrastructure of the equatorial segment of hamster spermatozoa during penetration of oocytes fournal of Ultrastructural Research 62 110-117

Moore HDM and Bedford JM (1983) The interaction of mammalian gametes in the female. Sperm/egg interactions in vivo. In Mechanism and Control of Animal Fertilization Ed. JF Hartmann pp 453-497. Academic Press, New York

Moore HDM and Hartman TD (1984) Localization by monoclonal antibodies of various surface antigens of hamster spermatozoa and the effect of antibody on fertlization in vitro. Journal of Reproduction and Fertility $\mathbf{7 0}$ 175-183

Okabe M, Matzno S, Nagira M, Mimura T, Kawai $Y$ and Mayumi TA (1990) Human sperm antigen possibly involved in binding and/or fusion with zona-free hamster eggs Fertility and Sterility 54 1121-1126

Parrington J, Swan K, Shevchenko VI, Sesay AK and Lai FA (1996) Oscillations in mammalian eggs triggered by a soluble sperm factor Nature $379364-368$

Primakoff P, Hyatt H and Tredick-Kline J (1987) Identification and purification of a sperm surface protein with a potential role in sperm-egg membrane fusion Journal of Cell Biology 104 141-149

Saling PM, Irons G and Waibel R (1985) Mouse sperm antigens that participate in fertilization. 1. Inhibition of sperm fusion with egg plasma membrane using monoclonal antibodies Biology of Reproduction 33 515-526

Sathananthan AH, Ng SC, Edirisinghe R, Ratnam SS and Wong PC (1986) Sperm-oocyte interaction in the human during polyspermic fertilization in vitro. Gamete Research 15317-326

Taggart DA, O'Brien $\mathbf{H}$ and Moore HDM (1993) Ultrastructural characteristics of in vitro fertilization in the grey short-tailed opossum, Monodelphis domestici. Anatomical Record 237 21-37

Takano H, Yanagimachi $R$ and Urch $U$ (1993) Evidence that acrosin activity is important for the development of fusibility of mammalian spermatozoa with the oolemma: inhibitor studies using the golden hamster Zygote 1 79-91

Toshimori K, Saxena DK, Tanii I and Yoshinaga K (1998) An MN9 antigenic molecule, equatorin, is required for successful sperm-oocyte fusion in mice Biology of Reproduction $5922-29$

Wassarman PM (1990) Profile of a mammalian sperm receptor Development $1081-17$

White JW (1992) Membrane fusion Science 258 917-924

Downloaded from Bioscientifica.com at 04/26/2023 11:18:29AM via free access 
Wolfsberg TG, Bazan JF, Blobel CP, Myles DG, Primakoff $P$ and White JM (1993) The precursor region of a protein active in sperm-egg fusion contains a metalloprotease and a disintegrin domain: structural, functional and evolutionary implications Proceedings National Academy of Sciences USA 90 10 783-10787
Yanagimachi R (1988) Sperm-egg fusion. In Current Topics in Membrane Transport Vol. 32 Membrane Fusion in Fertilization, Cellular Transport and Viral Infection Eds N Duzgunes and F Bronner pp 3-43. Academic Press, New York Yanagimachi R (1994) Mammalian fertilization. In The Physiology of Reproduction Eds E Knobil and E Neill pp189-317. Raven Press, New York 